\title{
Development of Korean Aural Rehabilitation for Infants
}

\author{
Jinsook Kim, Jieun Yoon \\ Research Institute of Audiology and Speech Pathology, College of Natural Sciences, Hallym University, Chuncheon, Korea
}

\author{
영아의 조기 청능재활 프로그램 개발 \\ 김 진 숙·윤 지 은
}

한림대학교 자연과학대학 언어청각학부, 청각언어연구소

\begin{abstract}
An application of newborn hearing screening program has allowed of the decreasing age for amplification system and increasing needs for aural rehabilitation. But structured rehabilitation programs for infants do not exist. Therefore the Korean Aural Rehabilitation for Infants (KARI) was developed based on 5 materials, Korean Infant Vocal and Articulate Development (KIVAD) list for setting baseline and target, Dan dong sib hoon for adapting Korean traditional infants' disciplining method, Short Fun Input for Modeling (SFIM) for systematic modeling technique for infants, Auditory Verbal Therapy (AVT) for emphasizing speech and listening, attachment parenting for fostering a child's socio-emotional bond. KARI also provides special parent education materials. KARI is now being tried for 5 infants who failed newborn hearing screening and shows good improvement. As the core program and materials were completed, utilizing to more hearing impaired infants will make more practical KARI with continuing supplementations and modifications in the future.
\end{abstract}

Key Words: Newborn hearing screening program, Korean aural rehabilitation for infants (KARI), Dan dong sib hoon, Attachment parenting.

Received: February 20, 2016 / Accepted: March 10, 2016

Correspondence: Jinsook Kim, Research Institute of Audiology and Speech Pathology, College of Natural Sciences, Hallym University, 1 Hallimdaehak-gil, Chuncheon 24252, Korea

Tel: +82-33-248-2213 / Fax: +82-33-256-3420 / E-mail: jskim@hallym.ac.kr

\section{INTRODUCTION}

청각장애 조기재활의 중요성에 대한 인식의 확대는 신생아 청력선별검사프로그램의 적용을 전 세계적으로 증가시키고 있 다. 우리나라도 보건복지가족부의 건강증진사업 중 하나로 신 생아 청각선별검사 시범사업이 2007년부터 시행되고 있다. 보 건복지가족부는 2007년 전국의 16 개 지역을 대상으로 실시한 1 차 사업에서 8,811 명의 신생아 중 15 명의 선천성 난청을 확진 하고 청각선별검사가 선천성 난청 여부를 확인하는 데 매우 중 요한 역할을 하는 것을 확인하였다. 따라서 시범사업을 2008년 에는 32 개 지역으로 확대 시행하였고, 최근에는 전국적으로 모 든 신생아를 대상으로 청각선별검사를 시행하는 것을 목표로 하고 있다(Park, 2015). 보건복지부의 보도 자료에 의하면 '선천 성 난청은 완치될 수 없어 언어-청각장애인으로 성장하나 출 생 직후 재활치료를 시작하면 언어-학습장애가 최소화되어 정
상에 가깝게 성장할 수 있으므로 조기발견이 중요하다고 하여 청각장애아의 조기발견과 조기재활의 중요성을 강조하였다 (Kim \& Choi, 2008).

이러한 경향은 이미 1982년부터 현재까지 영아의 난청 진단 과 재활의 가이드라인 및 권고기준을 제시하고 있는 미국 영아 청각협회(Joint committee on infant hearing, JCIH, 2007)에 서 발표한 내용에 근거하고 있다. JCIH의 발표 내용을 요약하 면 청각장애 영아의 경우 생후 1 개월 이내에 청력에 대한 청각 선별검사를 받고 3 개월 이내에 난청을 확진하며 6개월 이내에 청능재활을 받도록 권장하고 있다. $\mathrm{JCIH}$ 는 25년간 시행해온 프로그램을 종합하며 6 개월 이전에 조기재활을 시행한 청각장 애아동들이 20에서 40퍼센타일까지 언어 및 전반적 발달이 향 상되는 점을 강조하였는데, 이는 생후 6 개월 이내 혹은 만 1세 이전에 청능재활을 시작하면 그 이후 재활을 받은 아동보다 수 용 및 표현언어, 어휘발달, 어음산출, 사회·정서적 발달 등에 월 
등한 결과를 보인다고 한 여러 연구자들의 보고(Mayne et al., 1998; Yoshinaga-Itano et al., 2000; Nothern \& Downs, 2002) 와 일치한다.

$\mathrm{JCIH}$ 와 영어권의 많은 연구에서 입증된 것처럼 조기발견과 더불어 이후의 조기재활이 매우 중요하다. 그러나 우리나라 신 생아청각선별검사와 관련된 연구에서, 청각장애의 조기발견은 평균 5.2개월이나 재활은 일반적으로 24 개월로 지연되고 있음 이 밝혀져 이에 대한 개선점이 지적되었다(Choi \& Yoon, 2007). 또한 조기재활을 받지 못한 아동들에게 소요되는 사회적 비용 은 조기발견과 재활을 통하여 절감할 수 있다는 선행연구의 보 고(Moon et al., 2004) 등으로 시기 적절한 조기 재활의 실시가 중요한 과제로 부상하고 있으나, 국내에는 청각장애 조기발견 후 작용할 수 있는 체계적인 청능재활 프로그램이 없는 실정이 다. 최근 초기 발성의 발달단계를 연구하는 연구가(Pae \& Ko, 2010; Kim et al., 2012; Ha et al., 2014) 증가하고 있으나 국내 영아의 의사소통 발달에 대한 자료는 한 단어 이상 산출한 이 후의 자료이거나(Cho, 1984), 말이 산출된 이후인 2세 이후에 집중되어 있다(Choi, 2000). 따라서 국내의 영아의 청능재활 모 델은 발표된 자료가 미흡하고 콘텐츠가 완성되지 않아 실질적 적용이 어려워 우리나라 영아에게 적용할 수 있는 청각장애 영 아의 구조적인 청능재활 프로그램 개발이 매우 필요하다.

\section{DEVELOPMENT OF KOREAN AURAL REHABILITATION FOR INFANTS}

해외 영아의 청능재활 프로그램을 국내 영아에게 적용하기 에는 무리가 있다. 왜냐하면 한국어는 외국어와 특성이 달라 초기 발성 및 조음발달의 과정이 차이가 있고 목표와 진행 과 정이 다르기 때문이다. 또한 이 시기에는 놀이가 중요한데 민족 간 다른 문화적 정서로 다른 육아법과 특유한 놀이로 구성된 해외 프로그램을 그대로 해석하여 국내에서 사용하는데 한계 가 있다. 따라서 우리 민족의 문화와 정서에 맞는 육아법과 놀 이를 중심으로 모국어에 근거한 영아의 청능재활 프로그램이 필요하다. 그러므로 국내 영아를 위한 영아의 청능재활(Korean Aural Rehabilitation for Infants, KARI) 프로그램을 개발하 고자 하였다. KARI는 우리나라 청각장애 영아의 발달 특성과 우리나라 정서 및 문화를 반영하기 위해 다음 다섯 가지 콘텐 츠를 중심으로 개발하였다.

\section{국내 영아의 발성 및 조음발달 목록}

국내 영아의 발성 및 조음발달 목록(Korean Infant Vocal and Articulate Development list, KIVAD)은 1 24개월 우리나 라 영아의 발성자료를 분석하여 개월 별 발성발달 및 조음발달
내역을 정리하였다. 이는 청각장애 영아의 조기재활 시, 발성 및 조음발달의 기준선과 목표를 설정하고 청능재활 프로그램 진행에 목표와 기초자료를 제공할 수 있다.

\section{단동십훈}

단동십훈이란 단군시대부터 구전되어 내려온 우리 민족의 전통 육아법으로 아이와 엄마의 상호작용을 강조하는 10 가지 교훈이 담긴 동작놀이이다. 단동십훈(檀童十訓)은 불아불아 (弗亞弗亞), 시상시상(詩想詩想), 도리도리(道理道理), 지암지암 (持闇持闇), 곤지곤지(坤地坤地), 섬마섬마(西摩西摩), 업비업비 (業非業非), 아함아함(亞合亞合), 짝짝궁짝짝궁(作作弓作作弓), 질라아비 휠휠의(羅呵備 活活議)로 구성되어 있다(Kim \& Cho, 2012; Choi \& Yang, 2010). 각 훈의 의미에 따른 동작은 발달에 따라 적절한 월령에 적용하여 청능재활 및 언어발달에 응용할 수 있도록 하였다(Appendix 1).

\section{애착육아법}

'애착육아(attachment parenting)'란 용어는 주 양육자와 아 이가 맺는 정서적 유대관계(Bowlby, 1969)를 중심으로 스킨십 을 강조한 육아방법을 의미하며 William Sears에 의해 처음 사용되었다(Granju, \& Kennedy, 1999). 특히 생후 1년은 부모 의 행동이 아이의 두뇌에 영구적인 인상을 남길 수 있어 중요한 시기이므로 애착육아의 행동, 예를 들면, 모유먹이기, 안고 다니 기, 아기와 함께 자기, 아기 울음에 귀 기울이기 등을 KARI에 적용하여 영아시기에 정서적 안정과 청능재활의 효과를 높이고 자 하였다. 이는 우리나라 전통육아법과도 매우 유사하여 특히 국내 영아의 청능재활법에 적용하기에 적절하다. 특히 전통육 아와 유사한 점은 포대기를 이용하여 부모의 체온과 심장박동 을 아기가 느끼게 해주어 자궁과 유사한 환경 조성하기, 몸짓이 나 언어 전달에 최적 방법인 스킨십을 온돌의 생활패턴 속에서 자연스럽게 적용하기, 안고 자는 습관으로 수면 시 안정된 환경 조성하기 등이 있다(Noh, 2013).

\section{짧고 재미있게 받아들이는 모델링}

짧고 재미있게 받아들이는 모델링(Short fun input for modeling, SFIM)은 집중시간이 짧은 영아가 자극을 쉽게 받아들 일 수 있도록 짧고 재미있게 자극을 제시하여 따라 하기의 효 율성을 높인 독특한 구조의 방법이다(Figure 1). 구체적으로 말 이나 발성 모델링을 1 분간 적어도 하루 5 회 이상 제시하는데 1 분간의 모델링은 5 초 단위의 12 개 동일한 말이나 발성자극으로 구성된다. 5 초 모델링은 말이나 발성자극을 약 1 초씩 제시하고 영아가 모방할 수 있도록 약 4초의 기다리는 시간을 제공하는 방법이다. 다시 말해 모델링을 1 초간 제시하고 4 초간 아이의 눈 


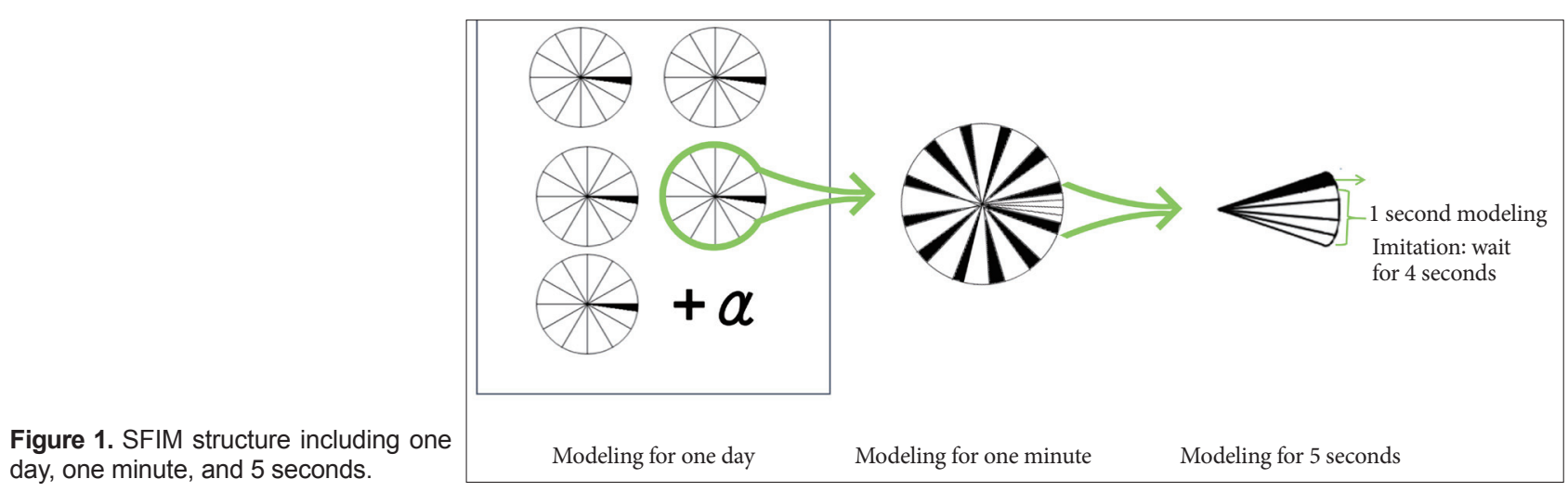

을 쳐다보면서 모방을 기다리는 행동을 통해 아이가 따라 하도 록 격려하고 말이나 발성자극에 대한 모방의 당위성을 알도록 하는 것이다. 이러한 과정을 통해 관련된 근육활동을 이해시키 고 듣기와 말소리와 발성산출의 연관성을 알게 할 수 있어 모방 의 효과를 향상시킬 수 있다. 정상발달기준의 말소리나 발성을 반복적으로 짧게 약 1 초간 제시하는 5 초 단위의 12 개의 자극과 모방 유도시간으로 구성된 1 분간의 모델링을 하루 중 아이가 기분이 좋고 모델링 자세가 되어 있을 때를 찾아 하루 5 회 이상 제시한다.

\section{청각구어법}

청각구어법(auditory verbal therapy, AVT)은 청각장애 아동 들이 청각을 이용하여 말하기를 배울 수 있다는 믿음 하에 청 각장애 아동들이 건청 아동과 마찬가지로 자연스럽게 듣고 말 하며 발달할 수 있게 하는 조기 청각언어재활 프로그램이다 (Pollack et al., 1997). AVT의 가장 큰 특징은 아동의 부모나 주 양육자가 적극적으로 재활에 참여하여 아동의 특성에 맞게 일상생활에 결합할 수 있게 부모를 돕는 것이다. 즉, 부모가 아 동을 양육하는 방식에 듣기와 말하기를 촉진하는 재활을 결합 하도록 하여 건청 아동들처럼 일상생활을 통해 듣기와 말하기 를 배우도록 하는 것이 주요한 목표이다(Brooks, 2002; Estabrooks, 1994). 듣기를 강조하는 AVT에서는 재활 세션에 Ling 6 측정을 강조하고 있다. Ling 6측정법은 가정에서 부모도 간단 하게 측정할 수 있는 듣기 검사법으로(Ling, 1976; Ling, 1989), 보청기나 인공와우의 기능을 확인하는 데 사용하며 주파수 별 로 기본 모음인 $/ \mathrm{m} /, / \mathrm{oo} /, / \mathrm{ah} /, / \mathrm{i} /, / \mathrm{sh} /, / \mathrm{s} /$, 6 개 음소로 구성된 소리를 탐지/변별/확인/이해의 4단계 청각기술발달에 따라 측정 하도록 되어있다. KARI도 국내 영아에 적절한 장난감, 소리, 놀 이, 노래 등을 이용하여 재구성한 Ling 6 측정법을 제시하였다.

\section{부모 상담 및 교육자료}

KARI는 부모교육중심 재활을 강조하며, 이를 위하여 부모
상담 시 사용할 체계적인 부모 상담 및 교육자료를 포함하고 있다. 예를 들어 ‘우리아이와 매일매일 어떻게 말할까요?', ‘질문 지', '일일 점검표, '월별 점검표, '영상교육자료' 등이다.

\section{우리아이와 매일매일 어떻게 말할까요?}

‘우리아이와 매일매일 어떻게 말할까요?'는 일상생활에서 영 아에게 청각언어 자극을 제시하는 방법을 상황 별로 엮은 부 모교육용 자료로 각 상황 별로 부모가 제시할 수 있는 언어자 극 방법의 설명과 그 예를 담고 있다. 총 16 개의 상황에는 아침 에 일어날 때' '기저귀 갈 때', '목욕 전후, '마사지 할 때', '젖 먹 일 때', '옷을 입고 벗을 때', '아이에게 밥 먹일 때', '책 읽기', '공 놀이', '아이 인형이나 곰 인형 가지고 놀기', '퍼즐 놀이', '소꿉놀 이', '놀이터에서 놀기(미끄럼틀, 그네)', '색깔찰흙 놀이', '빨래하 기', '산책하기'가 포함되어 있다.

\section{질문지}

가정에서 부모나 주 양육자가 실시하는 청능재활 과정 중 궁 금한 모든 내용과 난청 및 육아 전반에 대한 질문을 실시간으 로 매일 메모하게 한 후 재활 담당자가 답변해 줌으로써 좀 더 밀도 있는 부모상담이 이루어질 수 있도록 하였다.

\section{일일 점검표}

부모교육을 효율적으로 실시하기 위하여, 부모가 매일 영아 에게 집중적인 언어자극을 준 상황과 내용, 자발적인 발성 및 모델링 시 발성을 기록하도록 하여 부모가 가정에서 실시하는 재활 방법의 방향을 이끌어주는 지침표가 되도록 하였다.

\section{월별 점검표}

$1 \sim 3,4 \sim 5,6 \sim 7,8 \sim 9,10 \sim 11,12 \sim 13,14 \sim 15,16 \sim 17,18 \sim 19$, 20 21, 22 24개월로 나누어 총 11 개의 월령 구간별로 구성된 월별 점검표를 제작하였다. $\mathrm{KIVAD}$ 에 근거한 해당 월령 발성 목표를 제시하고 '영유아 청각 의사소통 행동 체크리스트' 문항 
도 각 월령 구간별로 점검하고, 청각언어인지를 향상시킬 수 있 는 놀이와 장난감을 제시한다. 특히 우리나라의 전통놀이인 '단 동십훈'의 해당 월령과 '애착육아법'등을 포함하여 가정에서의 청능재활 방법을 체계적으로 제시하는 지침표가 되도록 하였다.

\section{영상교육자료}

영상교육자료는 조기재활 전문가뿐만 아니라 부모에게도 유 익한 교육자료로, 부모와 아동간의 언어적인 상호작용을 촉진 하고 청각적 잠재력(auditory potential)을 극대화시키는 언어상 징행동(language signature behavior) 8단계와 듣기상징행동 (listening signature behavior) 8단계를 포함하고 있다. 언어상 징행동 8단계는 아동의 청각 및 언어발달 단계 설정을 위한 준 비(positioning), 아동의 소리(signals) 듣기, 의사소통 및 상호 작용을 위해 모델링 실시, 사물이나 행동의 이름을 말하기, 이 해하기, 스스로 말하기, 함께 말하기, 언어 확장 하기이다. 듣기 상징행동 8단계는 난청과 보장구에 대한 이해, 깨어있는 모든 시간에 보장구 사용하기, 보장구 관리, 소리 듣기에 집중하기, 소리에 대한 의미 있는 경험 제공하기, 소리에 대한 집중 유도하 기, 소리 변별 가르치기, 언어의 소리와 의미 연결시키기 등이다.

그 외 KARI의 독특한 구성과 진행과정에 맞는 'KARI 회기 계획서' '난청 영아를 위한 스마트한 육아법' 등의 자료도 포함 되어 있다.

현재 KARI는 신생아청각선별검사에서 확진된 언어발달지연 이 의심되는 영아 5 명에게 시험 적용 중이며 5 명 모두 청각 및 언어 발달 평가에서 매우 긍정적인 재활의 효과를 보이고 있다. 2 주마다 가정으로 방문하여 자연스런 환경에서 부모교육중심 의 재활을 실시하고 있으며, 한 세션 당 재활활동 및 부모교육 을 위한 상담을 포함한 총 소요시간은 평균 약 90 분이다. 시험 적용에서 조기 재활의 기초선을 확인하고 재활 후 3 개월 단위 로 영아의 진전도를 확인하기 위하여 발성 및 말소리, 듣기, 언 어 및 의사소통, 전반적 발달의 4개 영역을 Infant-Toddler Meaningful Auditory Integration Scale(IT-MAIS), Categories of Auditory Performance(CAP), Sequenced Language Scale for Infant(SELSI), Korean-MacArthur Bates Communicative Development Inventories(K-MBCDI)등을 포함하여 총 10개 의 검사를 실시하고 있다.

\section{CONCLUSION}

본 연구를 통해 청각장애 영아의 조기재활에 필요한 콘텐츠 와 방법을 구체적으로 제시하는 국내 영아의 청능재활 프로그 램을 개발하였다. '국내 영아의 발성 및 조음발달 목록, '단동십 훈, '애착육아법, '짧고 재미있게 받아들이는 모델링', '청각구어
법, '부모 상담 및 교육 자료' 등을 중심으로 이를 시험 적용하 여 밀도 있는 부모님의 피드백 등을 반영하고 재활에서 사용하 는 자료의 미비한 점을 확인한 후, 수정 및 보완 작업을 하고 있다. 예를 들면, 일일 점검표에 '자발적 발성 및 발화라는 용어 가 어머니들이 이해하기 어렵다는 의견이 나타나서 이를 '아이 가 스스로 한 말'로 수정하였다. 현재까지 완성된 KARI로 좀 더 많은 청각장애 영아를 대상으로 청능재활을 실시할 예정이 며, 그에 따른 지속적인 수정과 보완으로 우리나라 청각장애 영 아를 실질적으로 도울 수 있는 청능재활 프로그램으로 완성해 가고 있다.

중심 단어 : 신생아 청각선별검사·영아의 청능재활 프로그램· 단동십훈·애착육아법.

\section{Acknowledgments}

본 연구는 2015년 대한민국 교육부와 한국연구재단의 중견연구자 지원사업(인문사회:H00159) 지원을 받아 수행된 연구임(NRF-2015 S1-A5A2A01011541).

\section{REFERENCES}

Bowlby, J. (1969). Attachment and loss: Attachment. NY: Basic Books.

Brooks, B. M. (2002). My baby and me. MO: The Moog Center for Deaf Education.

Cho, M. H. (1984). Language acquisition research of Korean children: strategy model. Seoul National University, Seoul.

Choi, E. H. (2000). A study of vocabulary development of Korean children (unpublished master's thesis). Yonsei University, Seoul.

Choi, H. S. \& Yang, E. H. (2010). Korea's traditional parenting. Seoul, Korea: Shin Jung.

Choi, Y. H. \& Yoon, M. S. (2007). A study of early intervention for children with hearing impairment diagnosed through infant hearing screening test. Journal of Speech-Language and Hearing Disorders, 16(2), 173-187.

Estabrooks, W. (1994). Auditory-verbal therapy: for parents and professionals. WA: Alex Graham Bell Assn for Deaf.

Granju, K. A. \& Kennedy, B. (1999). Attachment parenting: instinctive care for your baby and young child. Simon and Schuster.

Ha, S. H., Seol, A. Y., \& Pae, S. Y. (2014). Vocal development of typically developing infants. Journal of the Korean Society of Speech Sciences, 6(4), 161-169.

Joint Committee on Infant Hearing. (2007). Year 2007 position statement: principles and guidelines for hearing detection and intervention programs. American Academy of Pediatrics, 120(4), 898-921.

Kim, H. S. \& Choi, S. S. (2008). 1.7 per 1,000 newborns were diagnosed with congenital hearing loss. Seoul: Korean Ministry for Health, Welfare and Family Affairs.

Kim, J. S., Ji, Y. S., \& Shin, H. U. (2012). A Study of infant's vocal production patterns for developing early aural rehabilitation program. Audiology and Speech Research, 8, 61-77.

Kim, K. H. \& Cho, M. J. (2012). Old future, the secrets of traditional child rearing. Seoul: LionBooks.

Ling, D. (1976). Speech and the hearing-impaired child: theory and practice. WA: Alexander Graham Bell Association for the Deaf.

Ling, D. (1989). Foundations of spoken language for the hearing-impaired child. WA: Alexander Graham Bell Association for the Deaf.

Mayne, A., Yoshinaga-Itano, C., Sedey, A. L., \& Carey, A. (1998). Expressive vocabulary development of infants and toddlers who are deaf or hard of hearing. The Volta Review, 100, 29-52. 
Moon, S. K., Park, H. J., Park, M. S., Kang, Y. S., Kim, Y., Choung, Y. H., et al. (2004). Clinical follow-up of hearing-impaired infants detected by newborn hearing screening. Korean Journal of Otolaryngology-Head and Neck Surgery, 47(9), 812-817.

Noh, H. S. (2013). Attachment parenting for child who has high self-esteem. Seoul: Prunyuka.

Northern, J. L. \& Downs, M. P. (2002). Hearing in children. Baltimore, MD: Williams \& Wilkins.

Pae, J. Y., \& Ko, D. H. (2010). Features of Korean infants' vocalizations according to the stages models: focused on 1 to 18 months. Journal of the
Korean Society of Speech Sciences, 2(2), 27-36.

Park, S. K. (2015). Newborn hearing loss and newborn hearing screening. Hanyang Medica Reviews, 35, 72-77.

Pollack, D., Goldberg, D. M., \& Caleffe-Schenck, N. (1997). Educational audiology for the limited-hearing infant and preschooler: an auditoryverbal program. Illinois: Charles C Thomas Pub Limited.

Yoshinaga-Itano, C., Coulter, D., \& Thomson, V. (2000). The Colorado newborn hearing screening project: effect on speech and language development for children with hearing loss. Journal of Perinatology, 20, 132-137. 


\section{APPENDIX}

Appendix 1. Specification of dan dong sib hoon

\begin{tabular}{|c|c|c|c|c|}
\hline 번호 & 단동십훈 & 의 & 동 & 시행 월령 \\
\hline 1 & $\begin{array}{l}\text { 불아불아 } \\
\text { (弗亞弗亞) }\end{array}$ & $\begin{array}{l}\text { 하늘로부터 온 아기의 생명을 존중하는 } \\
\text { 의미 }\end{array}$ & $\begin{array}{l}\text { 아기의 겨드랑이나 허리를 잡고 좌우로 흔들며 움직인다. } \\
\text { 척추신경, 하체 강화 }\end{array}$ & 6 개월 이상 \\
\hline 2 & $\begin{array}{l}\text { 시상시상 } \\
\text { (詩想詩想) }\end{array}$ & $\begin{array}{l}\text { 아기 몸에 우주가 있으니 우주의 섭리에 } \\
\text { 순응하는 의미 }\end{array}$ & $\begin{array}{l}\text { 아이를 앉혀놓고 두 팔이나 허리를 잡고 앞뒤로 흔든다. } \\
\text { 몸의 중심잡기 }\end{array}$ & 6개월 이상 \\
\hline 3 & $\begin{array}{l}\text { 도리도리 } \\
\text { (道理道理) }\end{array}$ & $\begin{array}{l}\text { 천지만물이 하늘의 도리로 생겼으니 } \\
\text { 이에 맞게 살라는 의미 }\end{array}$ & $\begin{array}{l}\text { 아이의 머리를 좌우로 흔든다. } \\
\text { 척수와 뇌수의 균형적 발전 활성화 }\end{array}$ & 4 5개월 \\
\hline 4 & $\begin{array}{l}\text { 지암지암 } \\
\text { (持闇持闇) }\end{array}$ & $\begin{array}{l}\text { 혼미한 것을 두루두루 헤아려 파악 } \\
\text { 하라는 의미 }\end{array}$ & $\begin{array}{l}\text { 두 손을 폈다 쥐었다 하는 동작 } \\
\text { 미세근육을 통해 심장의 혈액순환과 뇌의 기능 강화 }\end{array}$ & 3 4개월 \\
\hline 5 & $\begin{array}{l}\text { 곤지곤지 } \\
\text { (坤地坤地) }\end{array}$ & $\begin{array}{l}\text { 음향의 조화를 이루며 덕을 쌓으라는 } \\
\text { 의미 }\end{array}$ & $\begin{array}{l}\text { 한 손을 편 후, 반대 손 검지로 손바닥을 찍는 동작 } \\
\text { 손과 눈의 협응력 향상, 심장과 뇌의 활동 강화 }\end{array}$ & 8 9개월 \\
\hline 6 & $\begin{array}{l}\text { 섬마섬마 } \\
\text { (西摩西摩) }\end{array}$ & $\begin{array}{l}\text { 섬마섬마-바른길에 서며 독립적으로 } \\
\text { 살라는 의미 }\end{array}$ & $\begin{array}{l}\text { 엄마의 손바닥 위에 아이를 세워 올리는 동작 } \\
\text { 다리의 힘을 길러주며, 균형감각 향상 }\end{array}$ & 9 11개월 \\
\hline 7 & $\begin{array}{l}\text { 업비업비 } \\
\text { (業非業非) }\end{array}$ & 이치에 맞지 않는 행동은 삼가라는 의미 & $\begin{array}{l}\text { 양 팔을 뻗어 손바닥을 흔드는 동작 } \\
\text { 도에 맞지 않는 일이나 무서움을 가르칠 수 있음 }\end{array}$ & 4 5개월 \\
\hline 8 & $\begin{array}{l}\text { 아함아함 } \\
\text { (亞合亞合) }\end{array}$ & $\begin{array}{l}\text { \zh21ㅗ자를 소리 내어 아기가 작은 우주임을 } \\
\text { 알리는 의미 }\end{array}$ & 손바닥으로 입을 막으며 소리를 내는 동작 & 9 11개월 \\
\hline 9 & $\begin{array}{l}\text { 짝짝궁짝짝궁 } \\
\text { (作作弓作作弓) }\end{array}$ & $\begin{array}{l}\text { 천지의 조화를 꾀하고 하늘의 이치를 } \\
\text { 알리는 의미 }\end{array}$ & $\begin{array}{l}\text { 두 손바닥을 마주쳐 소리를 내는 동작 } \\
\text { 뇌 기능 활성화 }\end{array}$ & 6 8개월 \\
\hline 10 & $\begin{array}{l}\text { 질라아비 휠휠의 } \\
\text { (羅呵備 活活議) }\end{array}$ & $\begin{array}{l}\text { 어떤 질병도 없이 횔횔 날아 활기차게 } \\
\text { 자라라는 의미 }\end{array}$ & $\begin{array}{l}\text { 앉은 채로 두 팔을 날개처럼 벌리고 흔드는 동작 } \\
\text { 손과 눈의 협응력을 길러주며, 혈액순환 촉진 }\end{array}$ & 6개월 이상 \\
\hline
\end{tabular}

